\title{
Do Blackboard Accesses Predict a Student's Final Grade?
}

\author{
W. Conway Link, Carlos G. Spaht, II, Rogers Martin \\ Mathematics Department \\ Louisiana State University in Shreveport
}

\begin{abstract}
The Blackboard Learning System is a comprehensive e-Learning software platform from Blackboard Inc. It offers faculty flexible tools to incorporate technology and management into teaching and learning --- including announcements, course information, staff information, course documents, assignments, email and chat room communication, online assessments, and external links. With Blackboard, the instructor can post syllabi, multimedia files and other information that students may assess at any time from any location.
\end{abstract}

One of the advantages of the Blackboard system is that it makes available to the instructor the total number of accesses ("hits") per area, number of hits over time, user hits by hour of the day, user hits by days of the week, and number of hits by student. For this study, the investigators had two goals: (1) To fit a linear regression model to the data, using the number of Blackboard hits as the independent variable and the percent of the student's total possible number of points in the course as the dependent variable; and (2) By using the coefficient of determination, the square of the correlation coefficient, to determine how well the regression model fits the data.

Beginning with the spring 2001 term, the investigators saved all available Blackboard course statistics for each of their courses. More than 500 students and ten different courses including Elementary Algebra (7 sections), Mathematical Concepts (8 sections), Elementary Applied Calculus (4 sections), Discrete Mathematics (1 section), College Algebra (3 sections), Intermediate Algebra (2 sections), Analytic Geometry and Calculus II (1 section), Elementary Statistics (1 section), and Abstract Algebra II (1 section).

\section{The Problem}

Clearly, there are many factors that may influence a student's final grade in a mathematics course. Such factors include, but are not limited to the following: total number of credit hours in which the student is enrolled, number of hours each day the student is employed, number of semesters since the most recent pre-requisite course was completed, the number of hours the student spends in preparation, the number of mathematics courses completed, and a myriad of family related issues. In 1999 LSU-S adopted the Blackboard system, a comprehensive and flexible e-Learning software platform from Blackboard, Inc. which provides the instructor with the ability to manage announcements, course information, staff information, course documents, grades, communication (e-mail and chat rooms) and external links. 
One of the advantages of the Blackboard system is that it makes available to the instructor the total number of accesses ("hits") per area, number of hits over time, user hits by hour of the day, user hits by days of the week, and number of hits by each enrolled student. The associated histograms and pie charts are also available for viewing by the instructor.

Based on the belief that student usage of Blackboard would enhance their chance of success in a mathematics course, the investigators examined the "Is more better" question. In other words, was there a relationship between the number of blackboard hits and the student's overall final percent of total number of possible points in a mathematics course? Beginning with the spring 2001 term, the investigators saved all available Blackboard course statistics for each of their courses. More than 500 students and ten different courses covering a wide range of material and levels were included in the study. Those courses included were Elementary Algebra, Mathematical Concepts (a terminal math course primarily for Liberal Arts majors), Elementary Applied Calculus, Discrete Mathematics, College Algebra, Intermediate Algebra, Analytic Geometry and Calculus II, Elementary Statistics, Applied Statistics, and Abstract Algebra.

For the purposes of this study, three LSU-S mathematics faculty members collected Blackboard course statistics on $\mathrm{N}=557$ students for all courses they taught between and including the spring 2001 term and the summer 2002 term. Only students who completed the course by taking the final exam were included, regardless of whether they received a passing grade. For each of the 557 students, the number of Blackboard hits was paired with their final percentage score in the course (total number of points earned divided by total number of possible points).

The 557 students in the study were in no way a sample from any population of students at LSUShreveport, but the total number of students who took final exams in the courses covered by the three investigators during this time period. Nevertheless, the investigators decided to treat the study as a pilot study and use the coefficient of determination to measure the strength of the linear relationship or the proportion of variation in the student's final score, which can be explained by its relationship with the number of Blackboard hits.

\section{Results}

In the table which follows, the coefficient of determination are given first for all $\mathrm{N}=557$ students, followed by coefficients of determination for the individual courses and instructors. In the table, $\mathrm{N}$ is the number of persons in the set and $\mathrm{R}^{\wedge} 2$ is the coefficient of determination (the square of the correlation coefficient). 
1. Overall:

2. Beginning Algebra

3. Math Concepts

4. Ele. App. Calculus

5. College Algebra

6. Applied Statistics

7. Elementary Statistics

8. Intermediate Algebra

9. Calc./A.Geom II

0.022

10. Abstract Alg. II

0.001

11. Discrete Math

0.003

12. Instructor \#1

0.036

13. Instructor \#2

0.005

14. Instructor \#3

271

0.001

\section{Discussion}

In looking at the coefficient of determinations, $\mathrm{R}^{\wedge} 2$, one finds there is some variability $(0.001$ to 0.091 ) in these values. This, however, suggests that at a maximum, only $9.1 \%$ of the total variation in the student's final percent correct in their mathematics course, $\mathrm{Y}$, can be explained by its relationship with the number of Blackboard hits, X. Since the coefficients of determinations are so small, it can be concluded that the number of Blackboard hits do very little to explain the student's final percentage grade in the mathematics course.

When this investigation was begun, it seemed reasonable to propose that an increase in Blackboard hits would result in an increase in student percentage correct on their final grade. However, early in the data entry, it became clear that there was no pattern developing -- some of the better students had relatively few Blackboard hits. For example, two students who never accessed Blackboard (zero hits) had a final percent of $91 \%$ and $92 \%$, and eight of the 61 (13.1\%) who had a $90 \%$ or better as a final score accessed Blackboard 9 times or less. An additional eight students who had final percentages of $90 \%$ or more accessed Blackboard in excess of 100 times.

It should be noted that the three instructors used Blackboard differently. Two of them used it to offer different and more thorough explanations on topics than were given in class, as well as to post both assignments and announcements; the other used it only to post assignments. So, it may not be surprising that the coefficients of determination were different for the three instructors. Although not part of the original study, the arithmetic mean and the standard deviation for the number of hits by those students who had final percentages of $90 \%$ or more were determined for each instructor. 
Arithmetic Means and Standard Deviations for Number of Blackboard Hits for Students With $90 \%$ or More Final Percentage Correct

Instructor \#1 Instuctor \#2 Instructor \#3

$\begin{array}{llll}\text { Mean } & 41.81 & 69.68 & 46.33\end{array}$

$\begin{array}{llll}\text { Standard deviation } & 32.00 & 52.90 & 30.79\end{array}$

On another Blackboard-related topic, there is no reason to doubt that Blackboard's data gathering procedure and statistics are faulty, however, the reports for eight students were eyed with some suspicion by the investigators. One student had 1,549 reported hits (about 36 per day or 1.5 per hour), while seven others were reported to have between 272 and 376 hits (between 6.33 and 8.74 per day). The student with a reported 1,549 hits was removed from the study, but the other seven students were kept in.

\section{Recommendations}

Student's comments about Blackboard seem to be quite favorable, and the investigators believe the system is useful, especially for those unable to attend each class meeting. The investigators believe it would be of interest to expand the study in order to evaluate the possibility that one or more of the following may be associated with a student's percent of final grade:

1. Course level factor (freshman, sophomore, junior, senior, graduate). The vast majority of students in this study were enrolled in remedial or freshman level courses. Expanding the study to include more upper level courses may reveal that Blackboard is more helpful at one level than another.

2. Instructor factor: It was noted that even among the three investigators, there was some variation in the frequency and kind of information posted. In designing a new study, the frequency and kind of information to be posted by the instructor could be established in advance.

3. Theory versus applied factor: It may be that in mathematics, engineering, and sciences the unavailability of symbols and graphing necessary for communication in theory-based courses may limit the use of Blackboard in those classes. 


\section{W. CONWAY LINK}

Mr. Link serves as an Assistant Professor of Mathematics at Louisiana State University in Shreveport.

Since 1985, he has developed and coordinated programs for academically talented students and has taught the probability/statistics and discrete math components of LaPREP. His research interests include statistics and education.

\section{CARLOS G. SPAHT, II}

Dr. Spaht serves as Professor of Mathematics at Louisiana State University in Shreveport. For several years he has raised funds for and directed LaPREP, a nationally acclaimed intervention program in engineering, math and science for high-ability middle and early high school students. His research interests include intervention programs and Abstract Algebra.

\section{ROGERS MARTIN}

Mr. Martin serves as Instructor of Mathematics at Louisiana State University in Shreveport. For several years, he has taught algebra and discrete math classes. His research interests include applied math, computer science, and education. 